\title{
Experiences Determining the AC Current Rating of HTS Tapes in Power Transformers
}

\author{
A. C. Lapthorn, I. Chew, W. G. Enright and P. S. Bodger \\ Electrical and Computer Engineering \\ University of Canterbury \\ Christchurch, New Zealand \\ Email: andrew.lapthorn@pg.canterbury.ac.nz
}

\begin{abstract}
Two experimental high temperature superconducting transformers has been designed and built using Bi2223 HTS tape. The transformers are unique in that the magnetic circuit is comprised of air and a silicon steel partial core. The first transformer failed during a full load endurance run and an investigation was carried out to determine the cause of the failure. The cause was believed to be from operating the HTS windings close to critical conditions. A method of determining the ac current rating of the HTS tape was developed and applied to the second transformer. This second transformer was tested successfully under load for several hours.
\end{abstract}

\section{INTRODUCTION}

Early superconductors required temperatures of only a few Kelvin for superconduction and their application was very limited. The discovery of high temperature superconductors (HTS) in 1986 [1] with transition temperatures $\left(T_{c}\right)$ exceeding $77 \mathrm{~K}$ enabled liquid nitrogen $\left(\mathrm{LN}_{2}\right)$ to be used as a coolant. This paved the way for the application of these new materials into power system devices. Wire made from bismuth strontium calcium copper oxide (BSCCO) and more recently yttrium barium copper oxide (YBCO) has been used many power system devices such as fault current limiters [2], [3], power cables [4] and power transformers [5], [6].

A HTS conductor will only be superconducting so long as the magnetic field density, temperature and conductor current are below critical limits, (Fig. 1). If the limits are exceeded the conductor will change from a superconducting state to a resistive state. If this happens, the HTS conductors may experience catastrophic temperature rise. Due to their small cross sectional area, they may fail like a fuse, unless the supply current is otherwise interrupted.

This paper presents some experiences in determining the ac current rating for partial core transformers (PCT) that utilise HTS windings. Two high temperature superconducting partial core transformers (HTSPCTs) have been designed and constructed at the University of Canterbury [7], [8] using generation 1 (G1) BSCCO HTS wire. The first transformer failed as a result of operating too close to the critical conditions of the HTS windings. The second transformer has been tested successfully up to the rated current.

\section{iI. Partial Core Transformers}

PCT have been designed as an alternative to full core transformers, the difference being that the outer limbs and

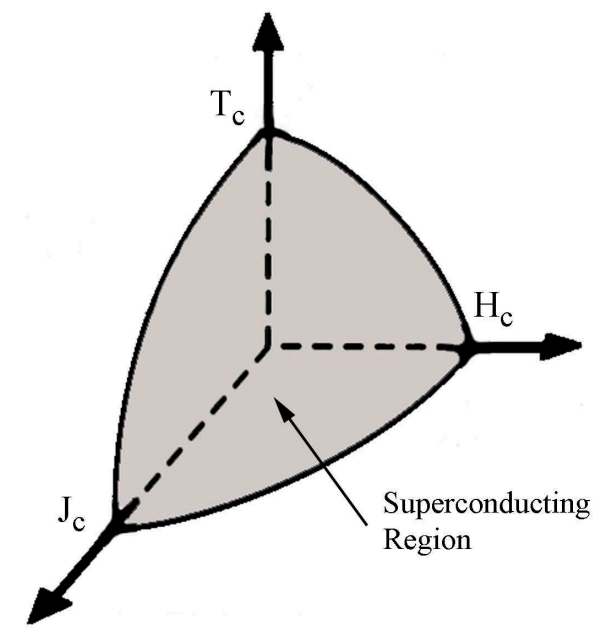

Fig. 1. A diagram illustrating the critical limits of a HTS wire

connecting yokes are absent from the PCT (Fig 2) [9], [10]. This means that the magnetic circuit for a PCT consists of the core and the surrounding air, which results in a high magnetic reluctance. A significant reason why there are not PCT in the power system is because the copper losses and efficiency can be poor due to the high magnetising current. The machine can be large because of the larger cross-section of conductor size required due to the extra magnetising current.

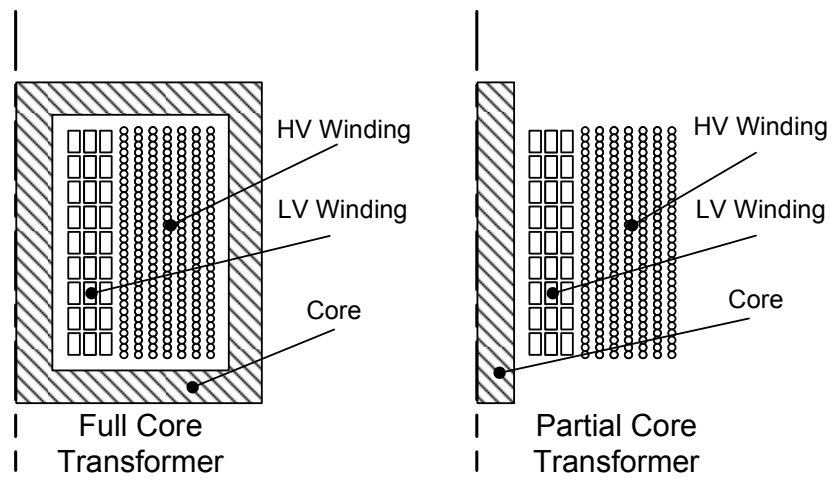

Fig. 2. A cross-sectional view of the differences between full core and partial-core transformers 


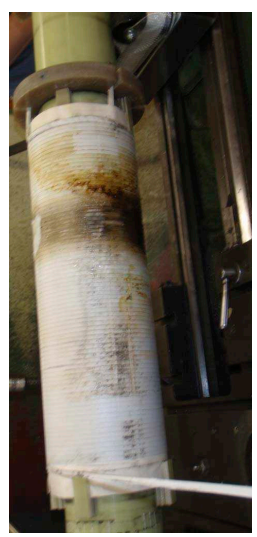

(a) Outside Winding

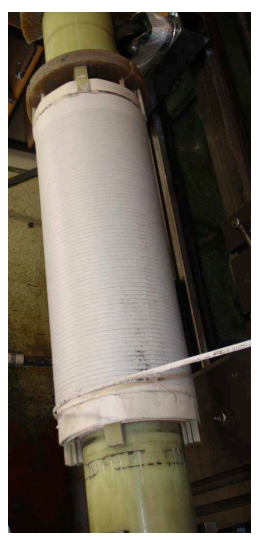

(b) Middle Winding

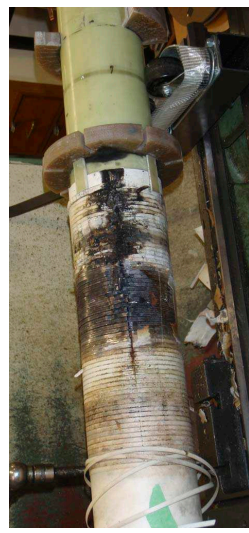

(c) Inside Winding
Fig. 3. Photographs of unwinding the HTS PCT after the failure

However, the application of HTS eliminates these issues, i.e. very low conductor losses and small cross-sectional area, allowing for a very compact and light PCT. Furthermore, what is also important is that the problematic magnetising current reduces with the square of the number of turns, (Equation 1).

$$
X_{m}=\omega L=\omega \frac{N^{2}}{\Re},
$$

where $X_{m}$ is the magnetising reactance, $\omega$ is the angular frequency, $L$ is the inductance of the winding, $N^{2}$ is the number of turns of the winding and $\Re$ is the reluctance of the magnetic flux path. Small increases in HTS wire length and therefore number of turns, gives significant reductions in magnetising current without increases in losses if HTS is applied. A disadvantage of the PCT is the cost of the HTS wire. However, as with other technologies, the price of HTS is likely to reduce significantly as the technology matures.

\section{THE NEED For A CURRENT RATING}

The need for a suitable ac current rating became clear with the failure of the first HTSPCT in 2009 [11], [12]. The transformer was designed as a single phase, $50 \mathrm{~Hz}, 230 / 115 \mathrm{~V}$, $15 \mathrm{kVA}$, HTS partial core device. Open circuit, short circuit and load tests were successfully performed on the transformer. The transformer was also used in a demonstration of a large Lightning Arc Drawing [13] where the load was approximately $25-30 \mathrm{~A}$ at $230 \mathrm{~V}$ with a power factor of about 0.8 lagging. The transformer performed well during several demonstrations each of which lasted approximately 5 minutes.

The failure occurred during a full load endurance test. The $230 \mathrm{~V}$ winding was conducting $65 \mathrm{~A} \mathrm{rms}$ into a resistive load when the secondary voltage collapsed followed by a large cloud of nitrogen gas venting from exhaust valve. Resistance tests on the primary winding showed it was failed open circuit. Unwinding of the HTS wire showed the extent of the damage sustained to the $230 \mathrm{~V}$ winding (Fig 3).

The investigation into the cause of failure indicated that peak transport current was likely to have exceeded the magnetic field adjusted critical current for the HTS tape and caused localised quenching of the tape. With the HTS in a resistive state, the losses dissipated would have increased the temperature in the inner windings where the cooling was poorest. Eventually the increase in temperature would result in the insulation failing, shorted turns in the windings and final breakdown of the HTS. In order to prevent a future failure it has been necessary to determine a design adjusted critical current.

\section{HTS CRITICAL CURRENT}

To obtain a suitable ac current rating of a transformer, knowledge of the critical current properties of the HTS wire is needed. The critical current or $I_{c}$ value of a HTS tape as stated by a manufacturer is a dc value in self field. Below the $I_{c}$ value the electric field over the length of the tape, measured as a voltage, is effectively zero. As the current is increased the voltage over the length of the tape increases. This has been empirically described by a power law.

$$
E(I)=E_{c}\left(\frac{I}{I_{c}}\right)^{n}
$$

where $E_{c}$ is the electric-field criterion, usually $1 \mu \mathrm{V} / \mathrm{cm}$. Fig. 4 depicts self field $I_{c}$ measurements taken on a sample of the G1 HTS tape used in the HTSPCT. The sample was $50 \mathrm{~mm}$ in length and the measurements were taken at $77 \mathrm{~K}$ using a standard 4 point system. The measurements on this sample give $I_{c}$ of $123.8 \mathrm{~A}$ and the $\mathrm{n}$ value of 16.5 for Equation 2 .

The critical current is also a function external magnetic fields (B) and $I_{c}$ decreases with increasing B. Also the highly crystallographically anisotropic nature of HTS materials results in a strong angular dependence of applied magnetic field to $I_{c}$ and $\mathrm{n}$ [14]. Measurements of the $I_{c}(\mathrm{~B})$ dependence are given in Fig. 5 for fields parallel and perpendicular to the tapes wide edge. It is apparent from the measurements that magnetic fields perpendicular to the tapes wide surface have a greater effect on the $I_{c}$ of a HTS tape than parallel fields. In a transformer these fields appear as radial flux in the end winding regions.

\section{Magnetic Field Modelling}

Because of the effect on $I_{c}$ of external magnetic fields, it is necessary to know what the magnetic field throughout the

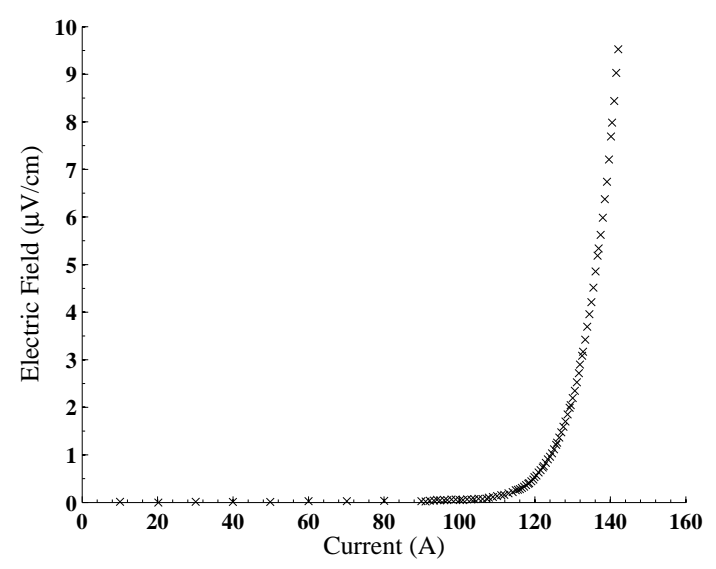

Fig. 4. $(E / I)$ measurement data from a sample of the $\mathrm{G} 1$ tape used in the HTSPCT at $77 \mathrm{~K}$ 


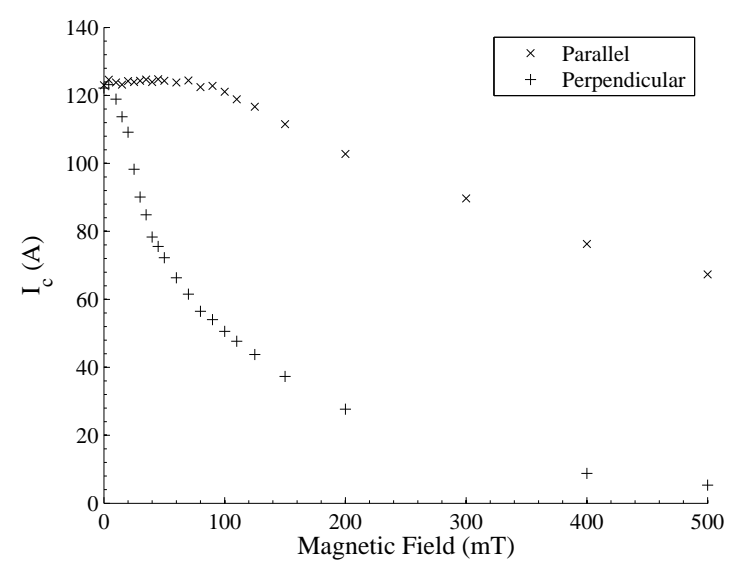

Fig. 5. $\left(I_{C}(\mathrm{~B})\right.$ measurement data for a sample of the G1 tape used in the HTSPCT at $77 \mathrm{~K}$

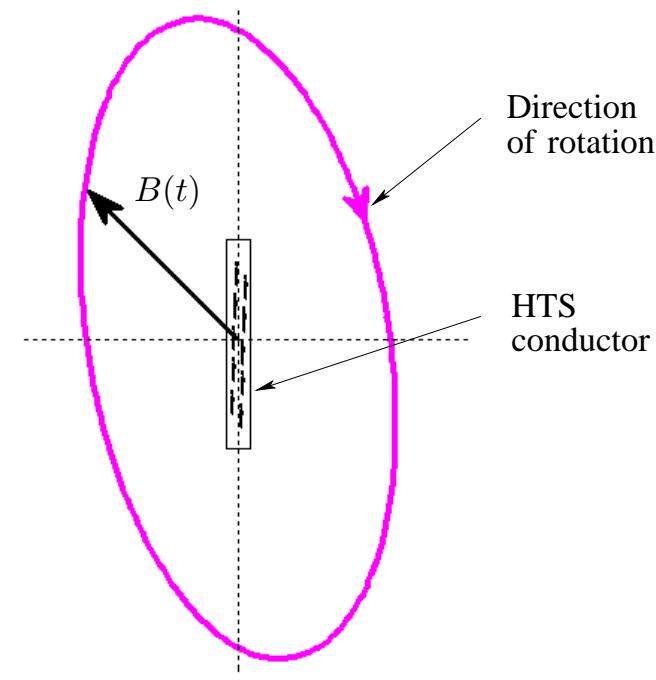

Fig. 6. Diagram of the elliptical nature of the magnetic field for a partial core transformer

transformer is before the ac current rating can be chosen. This is achieved by using finite element analysis (FEA). There is radial symmetry present in the partial core transformer design and as such a 2D time-harmonic simulation was used to model the magnetic field of the transformer.

Each layer of the PCT windings was modelled as a block of perfect conductor that covers all turns of that winding layer. The insulation between windings was modelled as air. This model was considered sufficient as the windings were packed close together.

The core was modelled as a single block of isotropic linear material with a relative permeability of 3000 . This model does not take into account the non-linear effects such as core saturation and radial flux not being restricted to the lamination plane. These non-linearities were assumed to have minimal effect on the global field distribution.

Results from the simulation proved interesting in that the magnetic field at a point in the winding did not have a static orientation throughout the simulation cycle. Instead the field tended to rotate in an elliptical pattern, Fig. 6, with the magnitude and orientation changing over time.

The time harmonic data from FEA software presents the magnetic field as a complex vector field. The $x$ and $y$ components of the field are complex scalars so that the magnetic field $\mathbf{B}$ is,

$$
\mathbf{B}=\left(x_{1}+j x_{2}\right) \mathbf{i}+\left(y_{1}+j y_{2}\right) \mathbf{j}
$$

where $\mathbf{i}$ and $\mathbf{j}$ are orthogonal unit vectors. The major and minor axes for the ellipse of $\mathbf{B}$ can be found from [15],

$$
\begin{aligned}
& \mathbf{B}_{\text {Major }}=|\sqrt{\mathbf{B} \cdot \mathbf{B}}| \Re\left\{\frac{\mathbf{B}}{\sqrt{\mathbf{B} \cdot \mathbf{B}}}\right\}, \\
& \mathbf{B}_{\text {Minor }}=|\sqrt{\mathbf{B} \cdot \mathbf{B}}| \Im\left\{\frac{\mathbf{B}}{\sqrt{\mathbf{B} \cdot \mathbf{B}}}\right\},
\end{aligned}
$$

The complex scalar components of the magnetic field were found for each turn in the transformer windings. The major axis of Equation 4 gives the magnitude and angle of the peak magnetic field for that turn. The data from the FEA modelling of the HTSPCT indicated the area of greatest radial flux was near the ends of the inside windings close to the core. In these regions, the major axis of the flux ellipse is almost perpendicular to the HTS tape's wide surface and has the greatest effect on the critical current.

\section{New Transformer Design}

By using the information on the critical current combined with the the analysis of the magnetic field distribution an ac current rating can be set for a new PCT. The design of the new HTSPCT is detailed in [8] and a summary is given in Table I .

TABLE I

Transformer Design PARAMETERS

\begin{tabular}{llc}
\hline Component & Parameter & Dimension \\
\hline Core & length & $200 \mathrm{~mm}$ \\
& diameter & $75 \mathrm{~mm}$ \\
\multirow{4}{*}{ Inside Winding } & material & laminated silicon steel \\
& layers & 8 \\
& length & $190 \mathrm{~mm}$ \\
& total turns & 296 \\
Outside Winding & material & Bi2223 G1 HTS \\
& layers & 8 \\
& length & $190 \mathrm{~mm}$ \\
& total turns & 296 \\
& material & Bi2223 G1 HTS \\
\hline
\end{tabular}

Analysis of the magnetic field under loaded conditions indicates the strongest radial flux is present on the ends of the inner most winding. This flux was near perpendicular to the tape's wide surface and had a peak value of $90 \mathrm{mT}$. According to Fig. 5, the magnetic field adjusted $I_{c}$ is equal to $55 \mathrm{~A}$. This results in an ac current rating for the transformer of $35 \mathrm{~A} \mathrm{rms}$ which allows for a safety margin.

Electrical testing of the completed transformer has been performed (Fig 7). A summary of the results can be found in Table II. The load testing was run over the period of several hours with no detrimental effects to the transformer. 


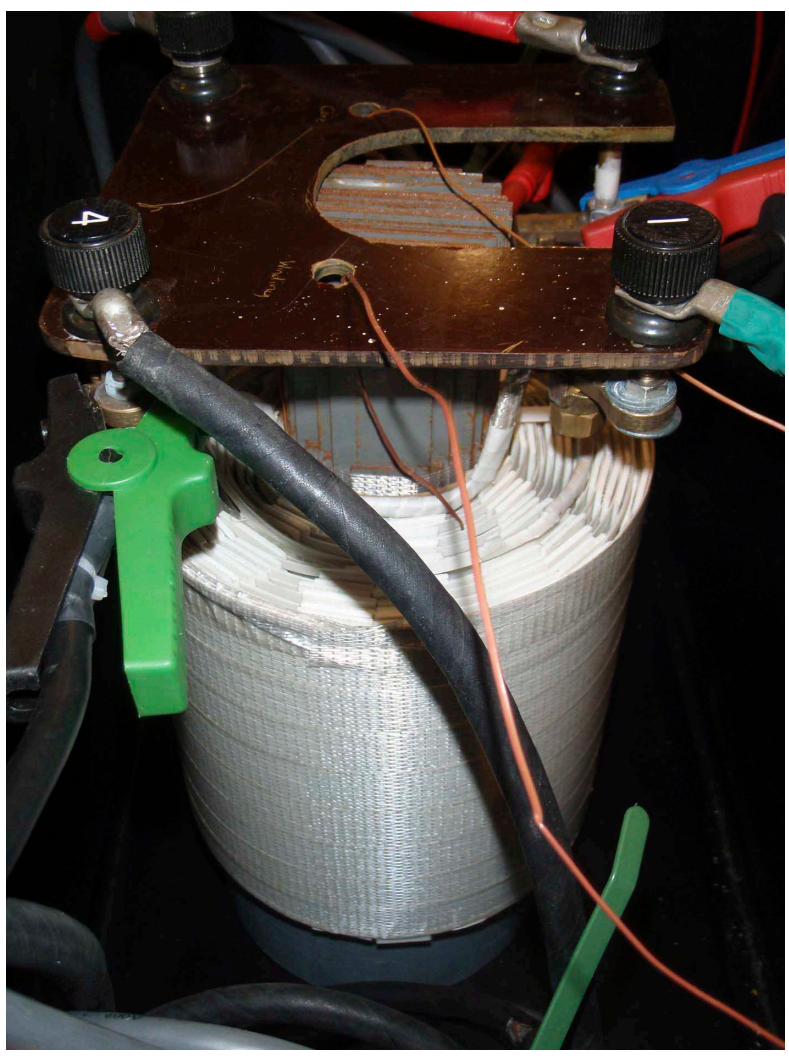

Fig. 7. Photograph of the HTSPCT prior to testing.

TABLE II

ELECTRICAL TEST MEASUREMENTS

\begin{tabular}{lc}
\hline \multicolumn{1}{c}{ Open Circuit Test } & Measured \\
\hline Parameter & 233 \\
\hline Inside winding voltage (V) & 25.1 \\
Inside winding current (A) & 219.7 \\
Outside winding voltage (V) & 184 \\
Inside winding real power (W) & \\
\hline \multicolumn{1}{c}{ Short Circuit Test } \\
Parameter & Measured \\
\hline Inside winding voltage (V) & 33 \\
Inside winding current (A) & 30 \\
Outside winding current (A) & 28 \\
Inside winding real power (W) & 80 \\
\hline & \\
Parameter & Measured \\
\hline Inside winding voltage (V) & 229.6 \\
Inside winding current (A) & 37 \\
Inside winding real power (kW) & 4.33 \\
Outside winding voltage (V) & 208.5 \\
Outside winding current (A) & 20.7 \\
Outside winding real power (kW) & 4.15 \\
Real power loss (W) & 180 \\
Efficiency (\%) & 95.9 \\
Voltage regulation (\%) & 10.14 \\
\hline
\end{tabular}

\section{CONCLUSIONS}

This paper has presented a method for determining a safe ac current rating for high temperature superconducting partial core transformers. The method was developed from lessons learned following the failure of a HTSPCT due to quenching of the HTS windings. The method uses information gathered from tests on a sample tape as well as FEA modelling of the magnetic field present in the winding space. The method was used on a new HTSPCT which was tested successfully for several hours under load.

\section{REFERENCES}

[1] J. G. Bednorz and K. A. Mller, "Possible high tc superconductivity in the ba-la-cu-o system," Zeitschrift fr Physik B Condensed Matter, vol. 64, pp. 189-193, 1986, 10.1007/BF01303701.

[2] E. Leung, B. Burley, N. Chitwood, H. Gurol, G. Miyata, D. Morris, L. Ngyuen, B. O'Hea, D. Paganini, S. Pidcoe, P. Haldar, M. Gardner, D. Peterson, H. Beonig, J. Cooley, Y. Coulter, W. Hults, C. Mielke, E. Roth, J. Smith, S. Ahmed, A. Rodriguez, A. Langhorn, M. Gruszczynski, and J. Hoehn, "Design and development of a $15 \mathrm{kv}, 20 \mathrm{ka}$ hts fault current limiter," Applied Superconductivity, IEEE Transactions on, vol. 10, no. 1, pp. $832-835$, mar. 2000.

[3] W. Paul, M. Lakner, J. Rhyner, P. Unternhrer, T. Baumann, M. Chen, L. Widenhorn, and A. Gurig, "Test of 1.2 mva high-tc superconducting fault current limiter," Superconductor Science and Technology, vol. 10, no. 12, p. 914, 1997.

[4] N. Steve, M. Nassi, M. Bechis, P. Ladi, N. Kelley, and C. Wakefield, "High temperature superconducting cable field demonstration at detroit edison," Physica C: Superconductivity, vol. 354, no. 1-4, pp. 49 - 54, 2001.

[5] Z. Jelinek, Z. Timoransky, F. Zizek, H. Piel, F. Chovanec, P. Mozola, L. Jansak, J. Kvitkovic, P. Usak, and M. Polak, "Test results of 14 kva superconducting transformer with bi-2223/ag windings," Applied Superconductivity, IEEE Transactions on, vol. 13, no. 2, pp. 2310 2312, jun. 2003.

[6] S. Schwenerly, B. McConnell, J. Demko, A. Fadnek, J. Hsu, F. List, M. Walker, D. Hazelton, F. Murray, J. Rice, C. Trautwein, X. Shi, R. Farrell, J. Bascuhan, R. Hintz, S. Mehta, N. Aversa, J. Ebert, B. Bednar, D. Neder, A. McIlheran, P. Michel, J. Nemce, E. Pleva, A. Swenton, W. Swets, R. Longsworth, R. Johsnon, R. Jones, J. Nelson, R. Degeneff, and S. Salon, "Performance of a 1-mva hts demonstration transformer," Applied Superconductivity, IEEE Transactions on, vol. 9, no. 2, pp. $680-684$, jun. 1999.

[7] P. S. Bodger, W. G. Enright, and V. Ho, "A low voltage, mains frequency, partial core, high temperature, superconducting transformer," in Australasian Universities Power Engineering Conference (AUPEC'05), The University of Tasmania, Hobart, Australia, Sep. 2005, p. CD.

[8] A. C. Lapthorn, I. Chew, and P. S. Bodger, "An experimental high temperature superconducting transformer: Design, construction and testing," in Electricity Engineers' Association of New Zealand Annual Conference (EEA'10).

[9] M. C. Liew and P. S. Bodger, "Partial-core transformer design using reverse modelling techniques," Electric Power Applications, IEE Proceedings -, vol. 148, no. 6, pp. 513-519, 2001.

[10] S. C. Bell, "High-voltage partial-core resonant transformers," Ph.D. dissertation, Univ. of Canterbury, Christchurch, New Zealand, 2008.

[11] I. Chew, A. Lapthorn, P. Bodger, and W. Enright, "Superconducting transformer failure: Testing and investigation," in Australasian Universities Power Engineering Conference (AUPEC'05), Adalide, Austrialia, Sep. 2009, pp. $1-5$.

[12] A. C. Lapthorn, I. Chew, W. G. Enright, and P. S. Bodger, "Hts transformer: Construction details, test results and noted failure mechanisms," Power Delivery, IEEE Transactions -, accepted for publication, Aug. 2010.

[13] S. C. Bell, W. G. Enright, K. Tunstall, and P. S. Bodger, "Lightning arc drawings - dielectric barrier discharges for artwork," in 15th International Symposium on High Voltage Engineering (ISH'07), Ljubljana, Slovenia, Aug. 2007.

[14] E. Talantsev, N. Strickland, P. Hoefakker, J. Xia, and N. Long, "Critical current anisotropy for second generation hts wires," Current Applied Physics, vol. 8, no. 3-4, pp. 388 - 390, 2008, aMN-3, Third International Conference on Advanced Materials and Nanotechnology.

[15] I. V. Lindell, Methods for electromagnetic field analysis. Hoboken, NJ: Wiley-IEEE Press, 1996. 